\title{
Analytical Method and Finite Element Method Wear of Disc Brake
}

\author{
Hailemariam Shegawu Abebawu
}

\begin{abstract}
This research focuses on wear of disc brake by method of analytical and finite element. An SUV car of DD6470C disk brake selected. Factors which considered as input parameters, such as the maximum allowable speed of the car as a constant throughout the work and by varying applied brake pressure. Analytical of the distribution of contact temperature along in the radial direction of disc brake caused by applied heat flux solved by using the separation of the variable method. Finite element simulation for contact pressure and von misses stress using; ANSYS workbench for the case of the structural analysis of disc brake was done by applying brake pressure and angular velocity. But, the thermal-structural, the maximum -contact temperature value of disc considered in addition. The contact pressure and von misses stresses were calculated analytically and ANSYS workbench results were presented in contour plot and numerically. The result shows that contact pressure, Von Misses stress and wear increased by increasing brake pressure in the case of the structure. And also parameters increase as increasing of both brake pressure and contact temperature of the disc in case of thermal-structural in all aspects like contact pressure, Von Misses and wear.
\end{abstract}

Keywords: contact pressure, contact temperature, wear, von misses stress,

\section{I.INTRODUCTION}

Recent cars have disc brakes attached on front and rear wheels. A brake is an artificial frictional resistance device is used to stop the motion of vehicles. The objective of the braking system is to convert the mechanical energy of moving the machine into some other form, which results in decreasing the speed of the machine. The thermal energy, caused by the kinetic energy of the machine and dry friction effects of the disc brake, is dissipated into the surroundings [1]. A disc brake fixed with the wheel. Two pads fitted inside a caliper mounted on the knuckle which mounted on the chassis. When the driver presses the pedal the brake cylinder pressure increases and the piston pushes the pads to contact with disc. The friction force between the brake pads and disc exerts braking torque on the disc which connected to the wheel and the subsequent friction between the tire and the road makes the car slow down. The brake operation phenomena affected by the friction material of disc and pad, braking pressure, angular velocity of disc brake and temperature. The coefficient of friction should be relatively high and keep a stable level irrespective of humidity, change temperature, corrosion and wear, exists of stone, water and mud [3].

Revised Manuscript Received on December 20, 2019.

* Correspondence Author

Hailemariam Shegawu Abebawu*, Department of Mechanical Engineering, Wollo University Kombolcha Institute of Technology, P.O. Box 208 Ethiopia.

(C) The Authors. Published by Blue Eyes Intelligence Engineering and Sciences Publication (BEIESP). This is an open access article under the CC BY-NC-ND license (http://creativecommons.org/licenses/by-nc-nd/4.0/)
During braking temperature at surface enhance, due to the effect, wear of parts, scoring, properties of material change and, degradation of material. Due to these reasons, this thesis focuses on surface wear of disc brake. Bayer defined wear as "damage to a surface as a result of relative motion for another substance" [4]. This thesis, the definition of wear as the degradation of material from a disc due to slid over pad. The classification of wear based on presence of lubricant and dry conditions [5].The presence of abrasive particles in wear is called abrasive wear. Unless, it is called sliding wear [5].

\section{II.MATERIAL AND METHODS}

\section{A. Materials Selection}

A disc brake made up gray cast iron was primarily used for this study. It's selected because of cast iron come up with advantage like thermal, mechanical, electrical and physical properties such as density, weight, wear resistance, high thermal conductivity, good thermal diffusivity, low cost and manufacture expense weight with against other disc brake friction materials like AL-MMC, ceramic- based composites and carbon composites [9]. High damping capacity, high hardness and excellent machinability were distinctive properties to gray cast iron frictional material. Main factors affecting thermal-structural stability of disc brake were elastic and thermal properties of gray cast iron material, applied brake pressure exerted on the pad and the fundamental design of disc brake. A few basic thermal properties of disc brake device are listed out as below [10]:Thermal capacitance (specific heat and density) is the capability to compilation heat. At the beginning, during braking condition, a frictional heat raise is compilation and during short braking, thermal capacitance is dominated.

Thermal conductivity is the capability to re-distribute the thermal energy. The peak temperature depends mainly on the disc brake material's conductivity due to long and lowintensity brake. But, the thermal conductivity has a few effects due to short brake. The coefficient of thermal expansion devastates the tendency into hot-spotting and thermal variation along the thickness of disc brake. The odd thermal expansion occurred due to the gradient of temperature over disc brake material.

\section{B. Analytical Conditions}

In order to show wear of disc brake by both finite element method and analytical method, this thesis considered the vehicle of model DD6470C used for it specifications to this thesis. Overall dimensions of disc and pad were used for the development of two dimensional and 3-D drawing.
\& Sciences Publication

(C) Copyright: All rights reserved.

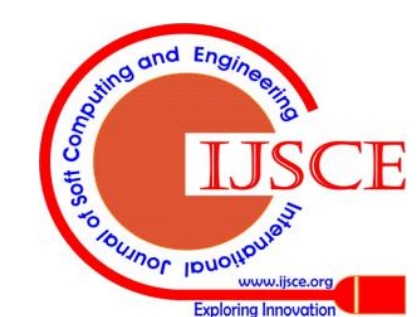


All necessary dimensions of disc and pads data and other necessary data related to this thesis were as shown below Fig.1.

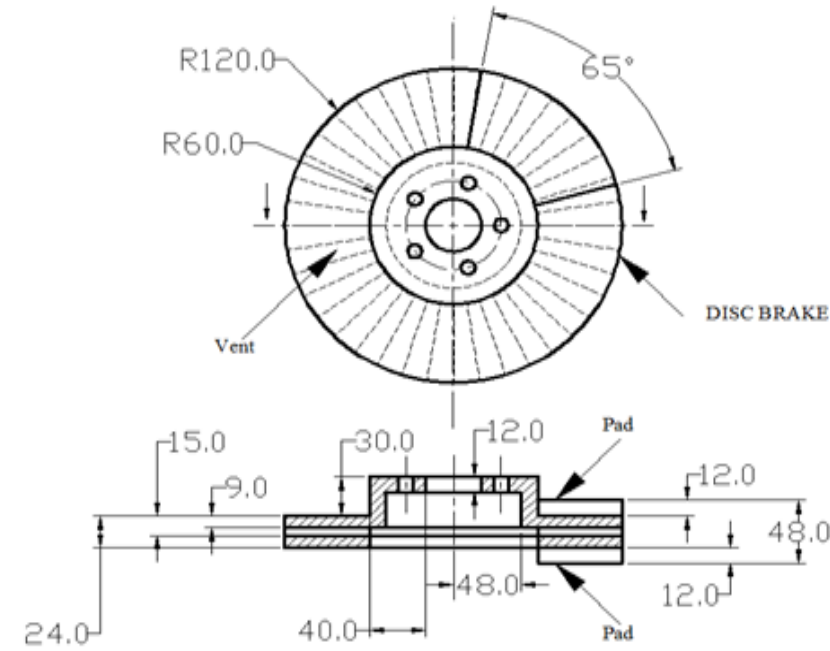

\section{All Assumptions for Thermal-Structural}

In order to minimize the work done, some assumptions have

1. The convection and conduction heat transfer processes only considered, but radiation ignored in this work due to the few amount up to $5 \%$ to $10 \%$ [12]. Indeed, the heat radiation only plays an important role at high temperature and low speeds.

2. In this thesis disc brake material assumed to homogeneous, isotropic, Poisson's ratio, young's modulus and coefficient of thermal expansion were to be uniform.

3. The domain is considered as axis-symmetric. The temperature field and applied hydraulic pressure are symmetry to the central plane of the brake disc.

4. The disc brake surfaces were exposed to convection heat transfer like vane, outer and inner rings, upper and bottom faces; and also had several values of coefficient of convection heat transfer.

5. A vehicle was moving along level surface road to overcome unnecessary potential energy and also ignored many losses.

6. The radius of the pad assumes circular to get initial Herztian contact pressure.

\section{Thermal-Structural Boundary Conditions}

The boundary and initial conditions of non-stationary ventilated disc brake rotor and pad as shown in Fig.2 is given as follow as below.
Fig.1. cross-section for ventilated disc and pads been taken [11].

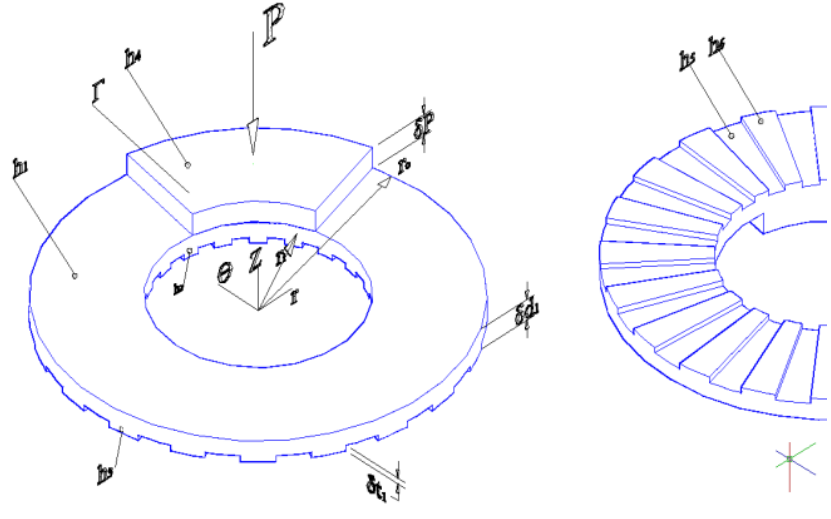

Fig.2. dimensioning ventilated disc and pad

The boundary and initial conditions of non-stationary ventilated disc brake rotor and pad is given:

$$
\left.\begin{array}{cc}
\sigma_{z z}(r)=-p(r) & r \in \Gamma \\
\sigma_{r z}(r)=-\mu p(r) & r \in \Gamma \\
q(r, t)=-\mu v(t) p(r) & r \in \Gamma
\end{array}\right\}
$$

\section{E. Analytical Contact Pressure Distribution for Structural}

Contact problems are one of the challenging issues of solid mechanics due to contact of bodies to be a deformable body, which results concentration of stresses in critical point in the body The analytical solution for contact pressure distribution can be written as:

$$
p(x)=\frac{F}{\pi a \sqrt{a^{2}-x^{2}}}
$$

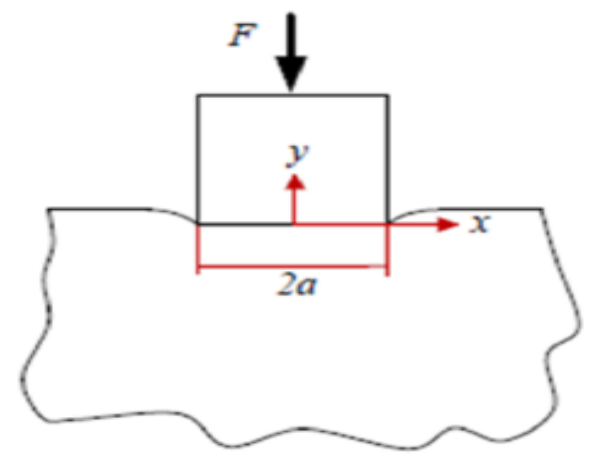

Fig.3. Flat on at contact configuration [14]

The contact pressure and the brake pressure were related by:

$$
P_{c}=\frac{P_{d}}{\left(1-\left(\frac{r}{a}\right)^{2}\right)^{1 / 2}}
$$

Analytical contact pressure at $r=0.95 a$, by considering nonphysical infinite stresses are predicted.

$$
P_{c}=\frac{0.999 * F_{c l a m p}}{\pi a\left(a^{2}-r^{2}\right)^{1 / 2}}=\frac{p_{d}}{\left(1-\left(\frac{r}{a}\right)^{2}\right)^{1 / 2}}=3.2 p_{d}
$$

\section{F. Analytical Wear for Structural}

In order to estimate wear depth raise, equation of modified Archard's used, within the contact as shown below:

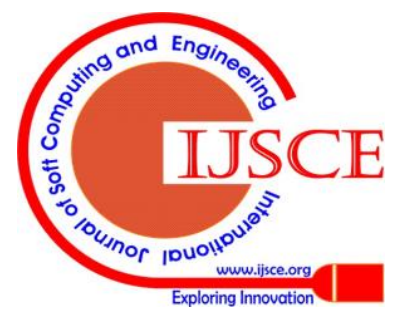




$$
\int_{h_{0}}^{h} d h_{s}=\int_{t_{1}}^{t_{2}} p_{c} k \omega_{o}\left(1-\frac{t}{t_{s}}\right) r d t
$$

The thickness of the worn material form disc brake with respect to brake pressure is express as follow as below:

$$
h_{s}=0.0141 p_{d}[\mathrm{~mm}]
$$

\section{G. Analytical Contact Surface Temperature}

During applied pressure exerted on disc-pad assembly, the frictional heat power developed across the contact surfaces was related to a form of heat flux given by:

$$
q(r, t)=\mu V(t) p(r)
$$

Distribution of temperature over the contact for analytically formulated in disc brake was the form of parabolic equation to that heat conduction is given by:

$$
\left.\begin{array}{c}
\frac{\partial^{2} T}{\partial r^{2}}+\frac{\partial T}{r \partial r}+\frac{1}{r^{2}} \cdot \frac{\partial^{2} T}{\partial \theta^{2}}+\frac{\partial^{2} T}{\partial z^{2}}=\frac{1}{K_{d}}\left(\frac{\partial T}{\partial t}+\omega \frac{\partial T}{\partial \theta}\right) \\
r_{i} \leq r \leq R_{o}, 0 \leq \theta \leq 2 \pi, 0 \leq z \leq \partial_{d}, t>0
\end{array}\right\}
$$
differential heat equation using non-dimensional parameters to contact temperature distribution with applied brake pressure:

$$
T(r)=55^{\circ} \mathrm{C}+\left(18.173 * 10^{-5} p_{d} \cos \left(\frac{14.966 r}{60}\right)-48.34 * 10^{-5} p_{d} \sin \left(\frac{14.966 r}{60}\right)\right)(9)
$$

The maximum contact temperature for disc brake at $\mathrm{r}=95.856 \mathrm{~mm}$ is given by:

$$
T_{c}(\text { disc })=516.43 p_{d}\left[{ }^{\circ} \mathrm{C}\right]
$$

\section{H. Analytical of Contact Pressure Distribution for Thermal-Structural Effects}

The steady-state maximum temperature rise at the contact interface is given by Tian and Kennedy [15] as:

$$
\begin{aligned}
T_{c} & =\frac{1.31 a_{t} \mu P_{t} V_{o}}{k_{d} \sqrt{1.2344+P_{e d}}+K_{p} \sqrt{1.23344+P_{e p}}} \\
a_{t} & =\left(\frac{3.848 k_{d}\left(1-v_{d}\right)}{\mu \omega_{o} \alpha_{d}\left(1+v_{d}\right) G_{d}}\right)^{1 / 2} \\
P_{e} & =\frac{V_{o} \rho_{d} c_{d} a_{t}}{2 k_{d}}
\end{aligned}
$$

Substituting all necessary values and also simplify, then we will get the relationship between contact pressure and contact temperature as shown below:

$$
P_{t}=56 P_{b}
$$

I. Analytical of Wear for Thermal-Structural Effects The sliding contact between the pad and disc causes a rise of temperature for both objects. This rising temperature also causes to contact pressure increase and wear coefficient was taken used to estimate the thickness of the worn material from disc surface as follow as:

$$
\int_{h_{o}}^{h} d h_{t}=\int_{t_{1}}^{t_{2}} p_{t} k \omega_{o}\left(1-\frac{t}{t_{s}}\right) r d t
$$

Wear depth with temperature effect respect to brake pressure:

$$
h_{t}=0.197 p_{d} \quad[\mathrm{~mm}]
$$

Prediction of convective heat transfer coefficient and solve

\section{J. Analytical of Von Misses Stress for Structural Effect}

The von misses the stress, for the axis-symmetric analysis, related to applied brake pressure:

$$
\sigma_{e s}=\sqrt{\left(\sigma_{z Z}^{2}+3 \sigma_{z r}^{2}\right)}=6.314 p_{b}
$$

\section{K. Analytical of Von Misses Stress for Thermal- Structural Effects}

To evaluate the von misses stresses caused by temperature effect:

$$
\sigma_{e t}=\frac{1}{\sqrt{2}}\left[\left(\sigma_{r}-\sigma_{\theta}\right)^{2}+\left(\sigma_{\theta}-\sigma_{z}\right)^{2}+\left(\sigma_{z}-\sigma_{r}\right)^{2}\right]^{1 / 2}
$$

After simplification and substitution of different parameters, the von misses stress for brake pressure will be given:

$$
\sigma_{e t}=8.65 p_{b}
$$

\section{III.FINITE ELEMENT METHODS AND CONDITIONS}

\section{A. Modeling of Disc and Pad Brake}

The assembly drawing of disc brake and pads is prepared by catia software. It saves as 'igs' to use ANSYS workbench. The assembly contained of the disc brake and two pads as shown below Fig.4. Open 'empty project' and then click on the 'Link to geometry file' and then browse, select the required model in 'igs' format. Click on the 'new simulation' option.

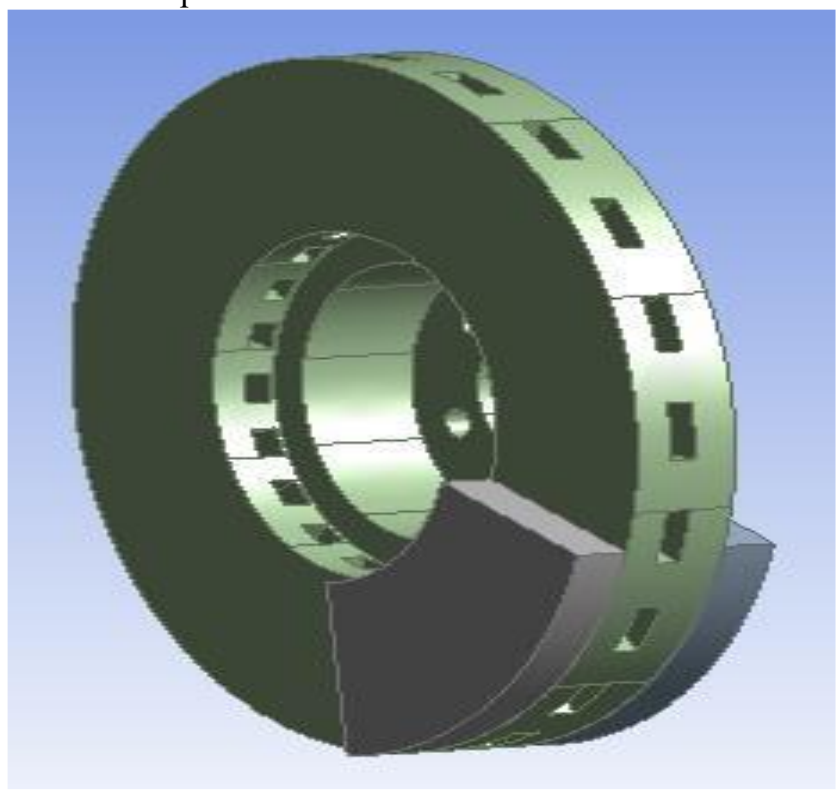

Fig.4. assembly of disc and pads

\section{B. Defining Material Properties of Study}

The disc brake made up of gray cast iron material ISO standard has much amount of carbon content with excellent thermal-physical properties and the brake pad has anisotropic elastic behavior, whose thermal-mechanical properties considered to be in this simulation in the contact pressure and von misses stress calculation result from analytical method. The appropriate material coefficient values for the disc and pads are like that of density, elastic modulus and poisson's where upload to ANSYS workbench has been used for analytical method. The procedure to write values on ANSYS Workbench, choice the engineering material file from the tab.

Published By:

Blue Eyes Intelligence Engineering 


\section{Contact Surface Definition for Structural}

Firstly, open the assembly drawing file on the statically structural tab list. Then, define the contact interface for disc and pad. ANSYS prepared to data automatically for predefined contact. The connection interface of the pad and disc is frictional contact; the value of co-efficient of friction as 0.35 and the interfaces of disc brake and pad is upper and lower faces respectively. The fundamental aim is that to change the interface treatments to "e adjust to touch"e. This option defines the type of contact between the selected bodies.

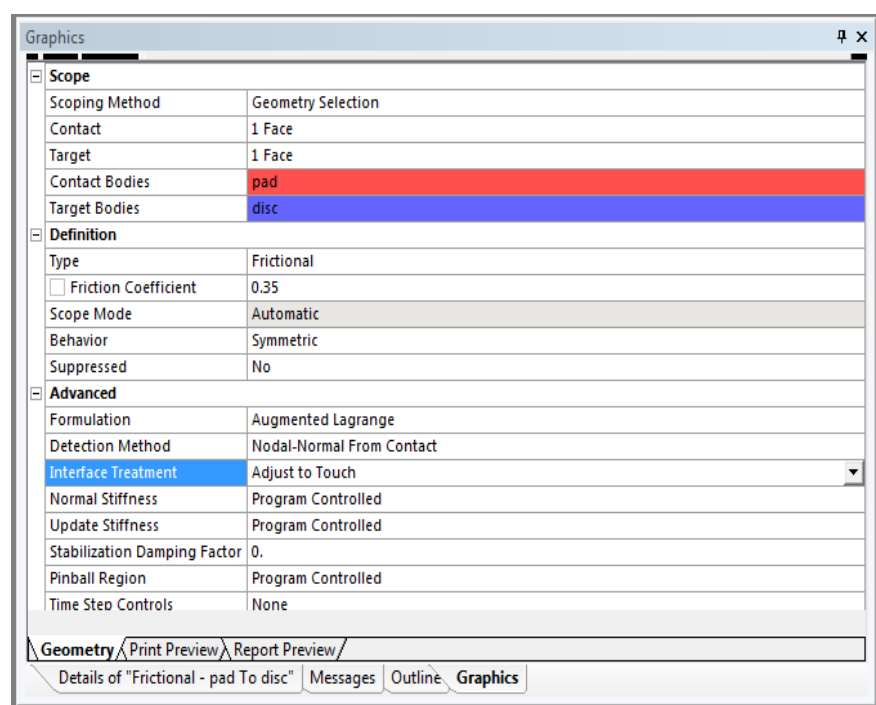

Fig.5.Image from ANSYS workbench showing contact of disc and pad

\section{Generation of Mesh}

The default values are insufficient to achieve correct results. In this work disc and pads were finely meshed with the "sizinge option in the menu. The value of coefficient element size was selected to be 0.0035 and also disc and pads contact surfaces were refinement. The Fig.5. Shown in bottom, the mesh model of disc and pads, with the given mesh value. There are about 203792nodes and 107665elements to the entire geometries.

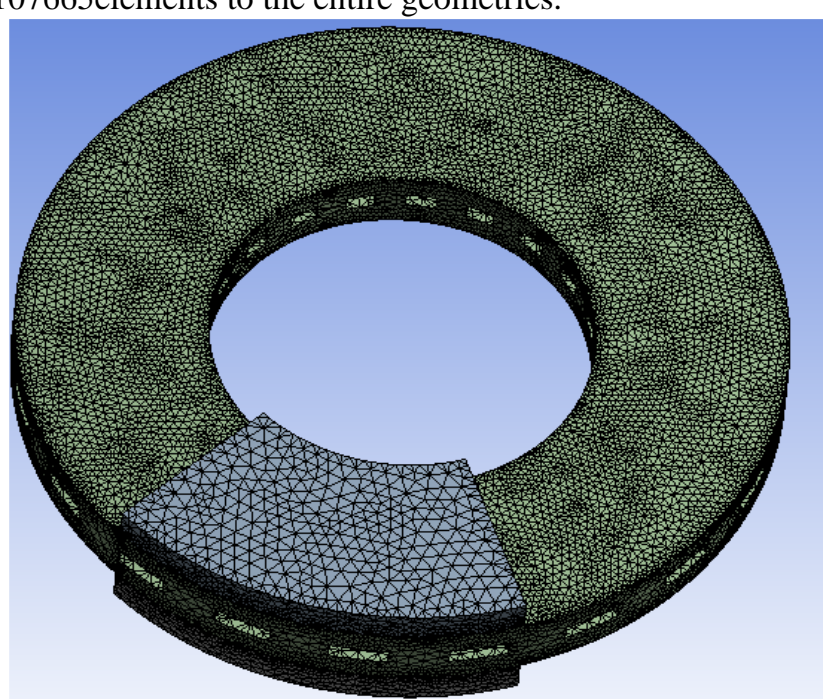

Fig.5.meshed model of disc brake with pad

\section{E. Boundary Conditions and Applied Loads to Structural}

The movement values along the $\mathrm{x}$ and $\mathrm{y}$ axis of the outside circular faces of the pads setting to be zero. During that time, z-axis movement was not fixed for pads. And also, the movement values along the $\mathrm{x}$ and $\mathrm{y}$ axis of the external and internal surfaces of the disc brake was not fixed. The variable applied brake pressure exerted on the upper surface applied in the top face of the pad. The selected data for the ANSYS workbench setting are summarized as follows:

Total time of simulation $=4.5 \mathrm{sec}$

Increment of time $=1 \mathrm{sec}$

Number of load steps $=1$

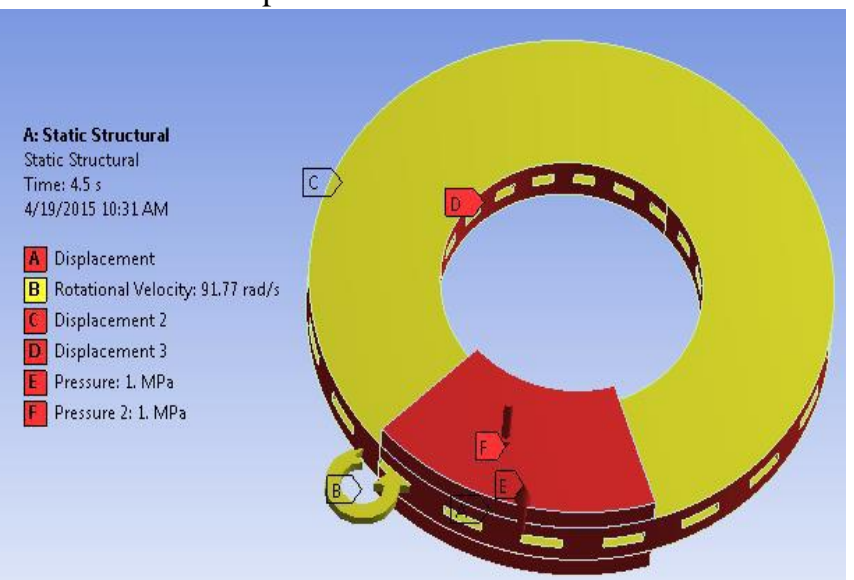

Fig.6. boundary conditions and loads statics structural

\section{F. Thermal-Structural}

In the thesis, the most important variables are temperature and pressure on the friction surface. So, we consider these applied loads in this thermal-structural work. The objective of this work is to determine the contact pressure, von misses stress and wear disc brake during braking condition of car. To predict these values, the same material properties, structural boundary condition and applied loads, model were used as discussed above for static structural. But some additional use full points to done these conditions were discussed as follows.

\section{G. Defining Contact Region for Thermal-Structural}

The assemblies drawing send to list of thermal-static structural; then define contact interface for disc brake and pad. ANSYS prepared to read files automatically for defined contact faces. The connection interface of the pad and disc is frictional contact; the value of co-efficient of friction as 0.35 and the interfaces of disc brake and pad is upper and lower faces respectively. The fundamental aim is that to change the interface treatments to "adjust to touch"e. During meshing assembly time, the nodes on potential contacting interfaces comprise the faces of contact elements that are four Gauss integral points are selected as contacting checkpoints. The Fig.7. below shows the image from ANSYS Workbench showing the contact defined for disc and pad.

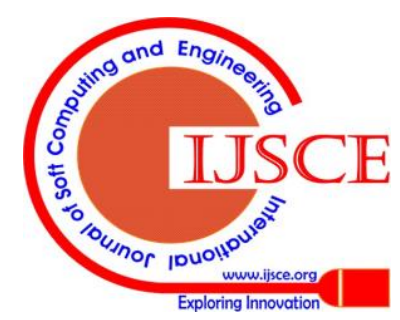




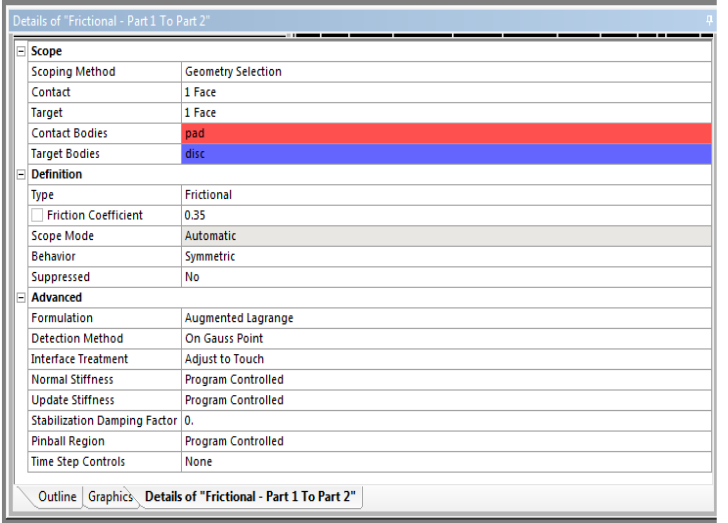

Fig.7. image from ANSYS workbench showing contact of disc and pad

\section{H. Mesh Generation}

The default value for meshes is insufficient to obtain the accurate results. In this thesis disc and the pad contact surfaces were refinement meshed with the "sizingee option in the menu. 0.001 element size was selected and then refinement at the contact interface to obtain required result for contact pressure, von misses stress and wear values. The mesh model as shown in Fig.8.below was with given mesh size value. There are about 352035 nodes and 223327 elements to the entire geometries.

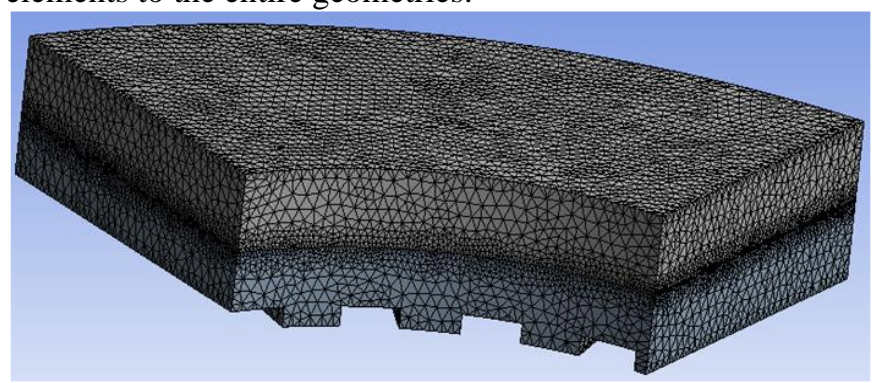

Fig.8. meshed assembly thermal-structural

\section{Boundary Conditions and Applied Loads to Thermal- Structural}

By applying the symmetric boundary condition, $1 / 8^{\text {th }}$ of the model is being simulated. The movement values along the $x$ and $y$ axis of the outside circular faces of the pads setting to be zero. During that time, $\mathrm{z}$-axis movement was not fixed for pads. And also, the movement values along the $\mathrm{x}$ and $\mathrm{y}$ axis of the external and internal surfaces of the disc brake was not fixed. The variable applied brake pressure exerted on the upper surface applied in the top face of the pad. At the same time, contact temperature load applied at the contact point where the applied load exerted. The thermal method conducted by selecting the transient and enters constant values of physical properties of disc brake and pad materials. The required data for ANSYS work bench setting are summarized as follows:

$>\quad$ Total time of simulation $=4.5 \mathrm{sec}$

$>\quad$ Increment of time $=1 \mathrm{sec}$ and Number of load steps $=1$

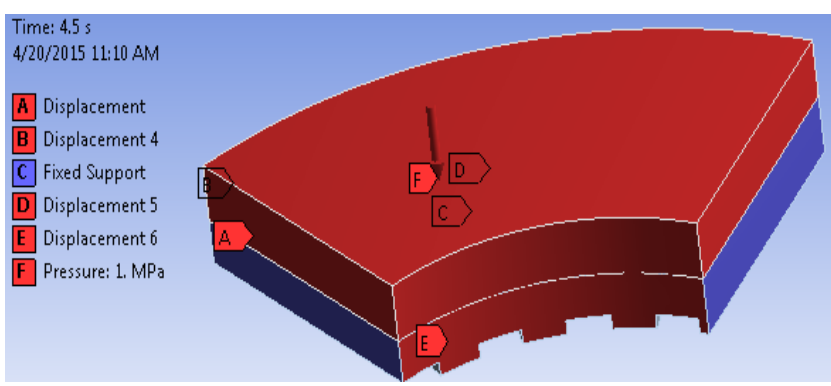

Fig.9.boundary conditions and loads thermal-structural

\section{IV.RESULTS AND DISCUSSIONS}

In this thesis work, the results of obtained by the analytical method and finite element method are like that of contact pressure, contact temperature, von misses stresses and wear of disc brake without and within temperature effect are discussed. Using both ANSYS Workbench software and analytical method, along with the boundary conditions, a variable brake pressure [MPa] is applied then we got value for these aforementioned parameters.

\section{A. Contact Temperature Variation of Disc Brake}

Fig..10.shows the contact temperature variation with time for different values of brake pressure at maximum contact temperature of the disc brake. It is noticed that the contact temperature decreases with the increase of time. This is due to the convection through the air and the convection through the vanes of the disc brake. The temperature gradient at frictional contact interfaces decrease as cooling raise at the point. The graph is plotted using analytical of contact temperature by Eq. (10) and we have got an approximate graph to literature review [6].

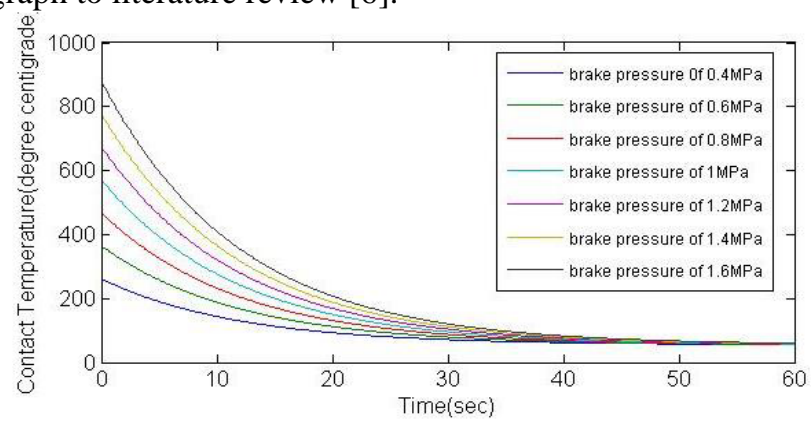

Fig.10. variation of contact temperature at $r=95.859 \mathrm{~mm}$ with time (different brake pressure in MPa)

\section{B. Contact Pressure by Structural Effect}

Fig.11. shows that contact pressure distribution is done by ANSYS workbench over disc brake during brake conditions when applied brake pressure is $1 \mathrm{MPa}$. As shown the contour plot maximum contact pressure is indicated by red color, which has a value of $3.134 \mathrm{MPa}$ and its minimum value, is 0 MPa also indicated by blue color. Also, the figure depicted that the maximum contact pressure is high at the outer and inner radius of the disc brake.

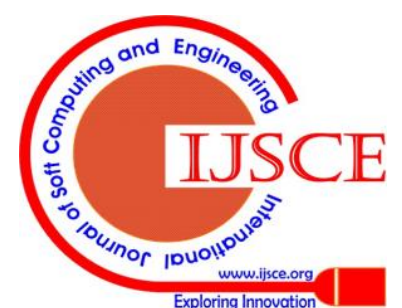






Fig.11. Contour Plot of Contact Pressure Distribution by Structural Effect

The same procedure used as Fig.11. and recorded maximum contact pressure to each applied brake pressure in (MPa), is done by ANSYS workbench. And the analytical method is done by using Eq. (4) for each applied brake pressure in $(\mathrm{MPa})$. And also maximum contact pressure the result is recorded in which done by it. The graph as shown in Fig.12., brake pressure to contact pressure, is done by both methods.

When we observation between the analytical and ANSYS workbench software results, both methods results show that the contact pressure increases with the increases of applied brake pressure. As shown in the Fig.12. below, the maximum deviation is occurring at a brake pressure of 0.4 $\mathrm{MPa}$. At this brake pressure, the analytical result shows that the maximum contact pressure is $1.28 \mathrm{MPa}$. And the ANSYS workbench software result shows that the maximum contact pressure is $1.3257 \mathrm{MPa}$. The maximum contact pressure between the analytical and ANSYS workbench results is done and results have a percentage error of $3.447 \%$. This value is in good agreement that the percentage error is less $10 \%$. Also, the figure shows the same result at $1 \mathrm{MPa}$ brake pressure for both analytical and ANSYS workbench. Most research papers were used this brake pressure to problems relate disc brake.

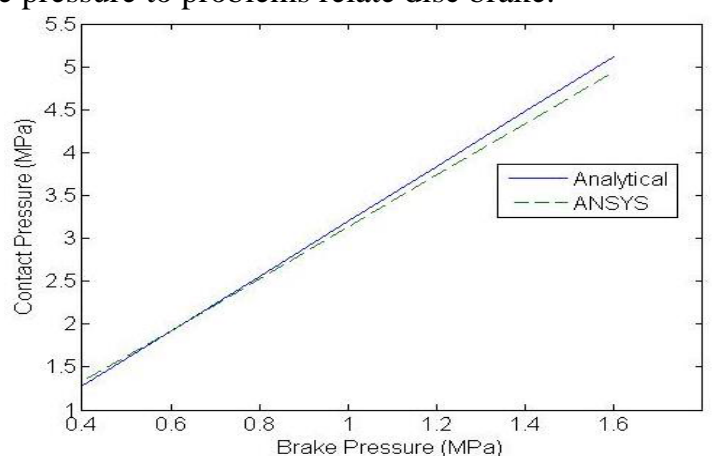

Fig.12. brake pressure to contact pressure done by methods

\section{Von Misses Stress by Structural Effect}

Fig.13. shows von misses stress without temperature effect done by ANSYS workbench software over disc brake during brake condition when applied brake pressure is $1 \mathrm{MPa}$. As shown in the contour plot, von misses' stress is indicating by red color, which has the value of $6.597 \mathrm{MPa}$ and its minimum value, is $869.82 \mathrm{~Pa}$ also indicate by blue color. Also, the figure depicted that the von misses stress is high at the around peripheral edge of the disc in contact with pad brake. The bottom side figure below shows the magnified image of contact pressure on the disc brake.

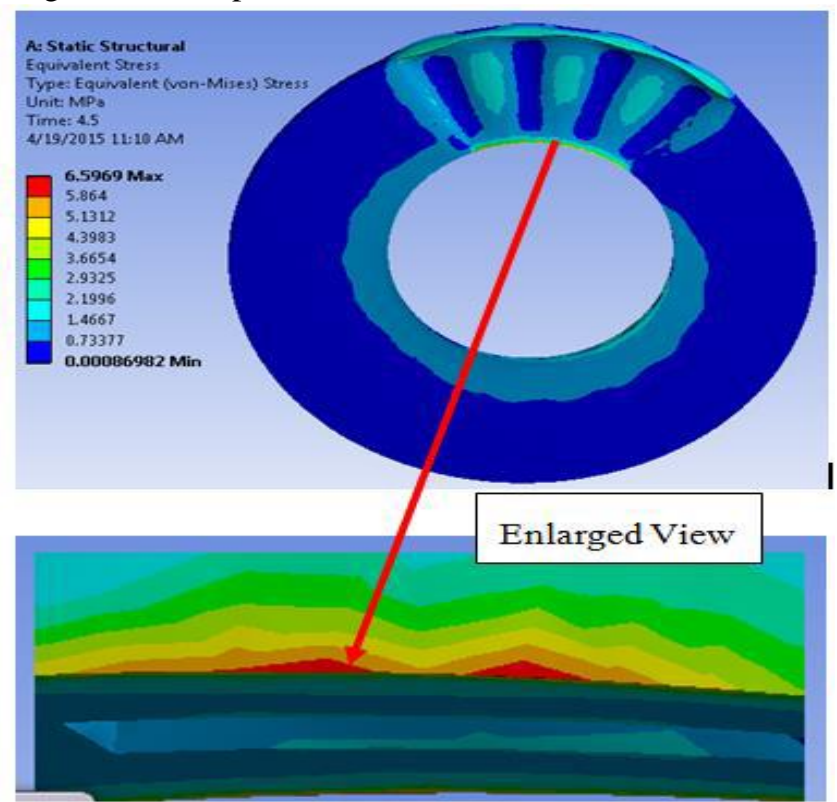

Fig.13. Contour plot of Von Misses Stress Distribution without Temperature Effect

The same procedure used as Fig.11., and recorded von misses stress to each applied brake pressure in (MPa), is done by ANSYS workbench. And the analytical method is done by using Eq. (17) for each applied brake pressure in (MPa). And also maximum von misses stress the result is recorded in which done by it. The graph as shown in Fig.14, brake pressure versus von misses stress which is done by both methods. When we observation between the analytical and ANSYS workbench software results, both results show that von misses stress increases with the increase of applied brake pressure. As shown in the graph below, the maximum deviation is occurring at the brake pressure of $0.4 \mathrm{MPa}$. At this brake pressure, the analytical result shows that the maximum von misses stress is $2.526 \mathrm{MPa}$. And the ANSYS workbench software result shows that the maximum von misses stress is $2.766 \mathrm{MPa}$. The maximum von misses stress between the analytical and ANSYS workbench results is done and results have a percentage error of $3.48 \%$. This value is the good agreement that the percentage error is less than $10 \%$. Also, the figure shows the $4.27 \%$ of error at $1 \mathrm{MPa}$ brake pressure for between analytical and ANSYS workbench. Most research papers were used this brake pressure to analyze problems relate to disc brake.
Published By:

Blue Eyes Intelligence Engineering \& Sciences Publication (C) Copyright: All rights reserved.

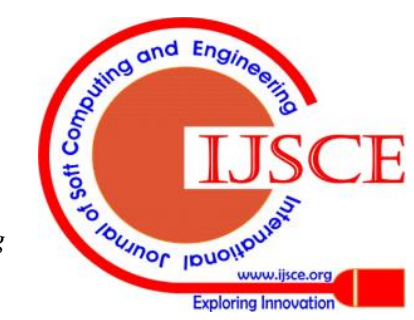




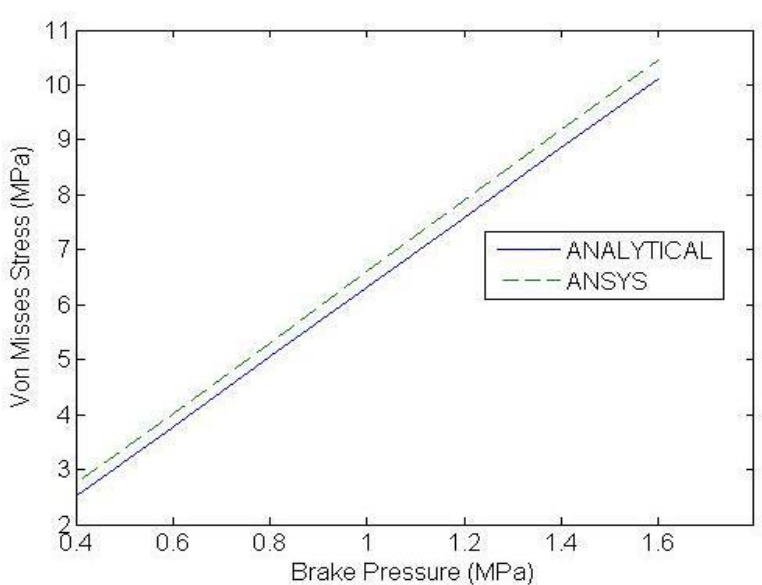

Fig.14. von misses stress for structural effect

\section{Contact Pressure by Thermal-Structural Effects}

Fig.15. shows contact pressure distribution done by ANSYS workbench software over disc brake during brake condition when applied both brake pressure is $1 \mathrm{MPa}$, corresponding respectively. As shown in the contour plot, the maximum contact pressure is indicating by red color, which has the value of $59.636 \mathrm{MPa}$ and its minimum value is $0 \mathrm{MPa}$ also indicated by blue color. Also, the figure depicted that the maximum contact pressure is high at near to the midpoint of inner and center radius of disc brake and portions of vanes in contact with pad brake.

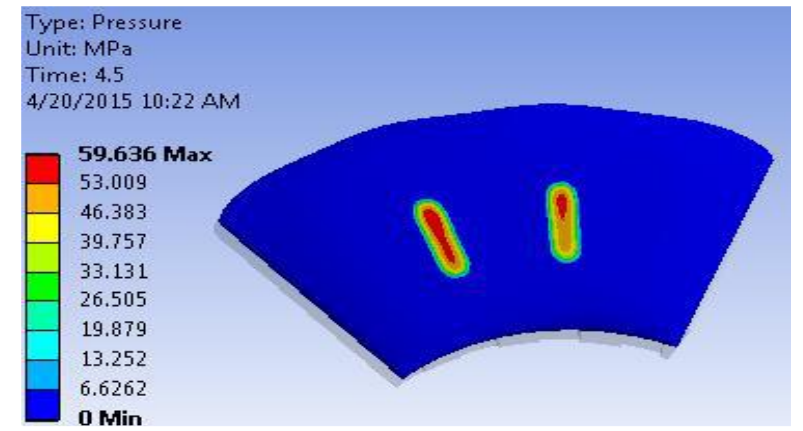

Fig.15. contour plot of contact pressure distribution by thermal-structural effects

The same procedure used as Fig.15., and recorded maximum contact pressure for each applied brake pressure in (MPa) and contact temperature of disc and pad, are done by ANSYS workbench. And the analytical method is done by using Eq.(14) to each applied contact temperature of disc brake. And also maximum contact pressure the result is recorded in which done by it. The Fig.16., as shown in brake pressure to contact pressure which is done by both methods. When we observation between the analytical and ANSYS workbench software results, both method show that the contact pressure increases with the increases of applied brake pressure. As shown in the graph below, the maximum deviation is occurring at the brake pressure of 1.6MPa. At this the brake pressure, the analytical result shows that the maximum contact pressure is $89.6 \mathrm{MPa}$. And the ANSYS workbench software result shows that the maximum contact pressure is $99.818 \mathrm{MPa}$. The maximum contact pressure between the analytical and ANSYS workbench results is done and results have a percentage error of $3.24 \%$. This value is good agreement that the percentage error is almost disc and pad temperatures are 571.3 MPa and 589.47MPa

equal to $2.8 \%$. Also, the figure show the $2.11 \%$ of error at $1 \mathrm{MPa}$ brake pressure for between analytical and ANSYS workbench. Most research papers were used this brake pressure to solve problems relate disc brake. Most research papers were used this brake pressure to problems relate disc brake.

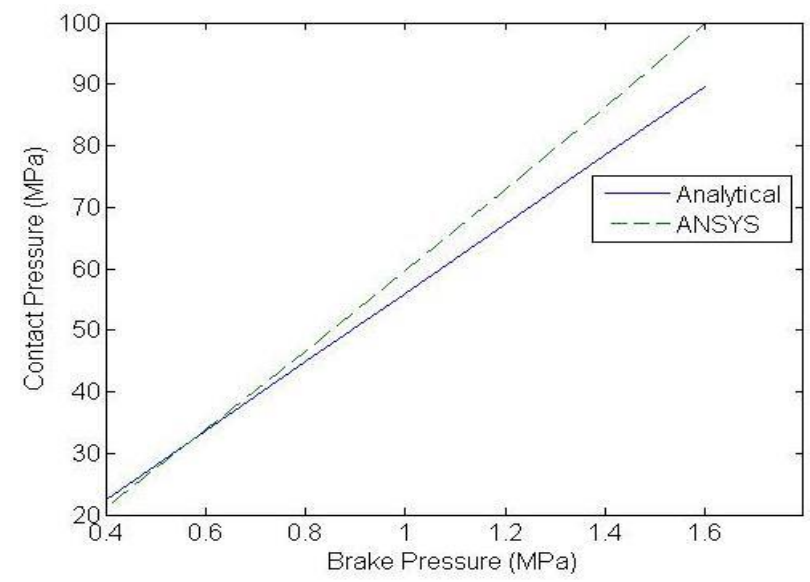

Fig.16. contact pressure within temperature effect versus brake pressure

\section{E. Von Misses stress by Thermal-Structural Effects}

Fig.17. shows von misses stress with temperature effect done by ANSYS workbench software over disc brake during brake condition when applied both brake pressure is $1 \mathrm{MPa}$, corresponding disc and pad temperatures are $571.3 \mathrm{MPa}$ and 589.47 MPa respectively. As shown the contour plot, maximum von miss's stress is indicating by red color, which has value of $9.8 \mathrm{GPa}$ and it minimum value is $0 \mathrm{GPa}$ also indicated by blue color. Also the figure depicted that the maximum von misses stress is high at axis-symmetry edge of disc in contact with pad brake. The bottom view figure show that magnified image of von misses stress at this point. But, if there is no axis-symmetric condition, the maximum von misses stress is near to inner radius of disc. So that analytical and ANSYS workbench results are same.

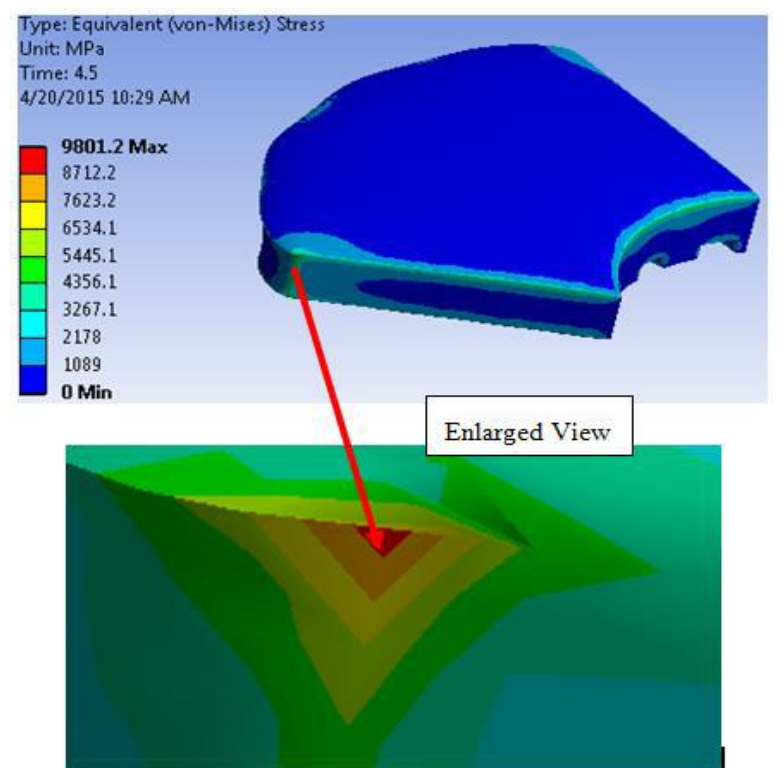

Fig.17. Contour Plot of Von Mise Stress Distribution within Temperature Effect

Published By:

Blue Eyes Intelligence Engineering

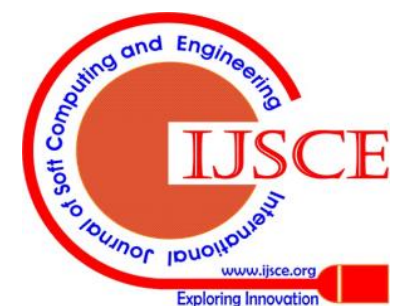


The same procedure used as Fig.17., and recorded maximum von misses stress with respect to each applied brake pressure in $(\mathrm{MPa})$ and contact temperature of disc and pad, are done by ANSYS workbench. And the analytical method is done by using Eq. (19) with respect to each applied contact temperature of disc brake in (MPa). And also maximum von misses result is recorded in which done by it. The graph as shown in Fig.18., brake pressure with respect to von misses stresses which are done by both methods. When we observation between the analytical and ANSYS workbench software results, both results shows that the contact pressure increases with the increases of applied brake pressure. As shown in graph below, the maximum deviation is occurring at brake pressure of $0.4 \mathrm{MPa}$. At this brake pressure, the analytical result shows that the maximum von misses is 3.46GPa. And the ANSYS workbench software result shows that the maximum von misses is $4.275 \mathrm{GPa}$. The maximum von misses stress between the analytical and ANSYS workbench results is done and results have percentage error of $1.86 \%$. Also the figure show the $1.17 \%$ of error at $1 \mathrm{MPa}$ brake pressure for between analytical and ANSYS workbench. Most research papers were used this brake pressure to solve problems relate disc brake.

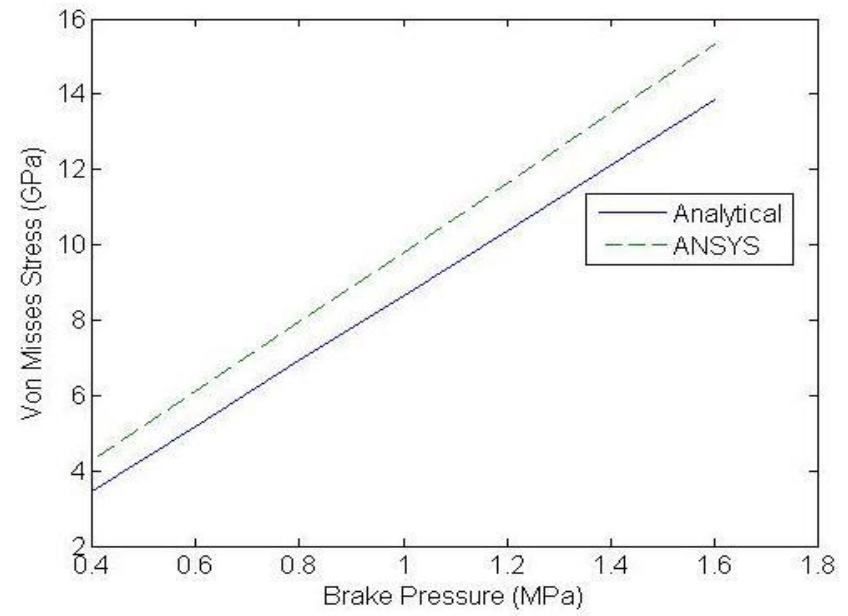

Fig.18. von mise stress within temperature effect versus brake pressure

\section{J. Wear Depth by Structural Effect}

The wear depth of disc brake without temperature effect is done both analytical method and ANSYS workbench from results of contact pressure. The analytical method of wear depth is done by using of Eq.(6) with in different brake pressures. And it also had done by ANSYS workbench by selection of maximum contact result from each applied brake pressure. As shown Fig.19., when we are observation between the analytical and ANSYS workbench software results, both method show that the wear depth increases with the increase of brake pressure.

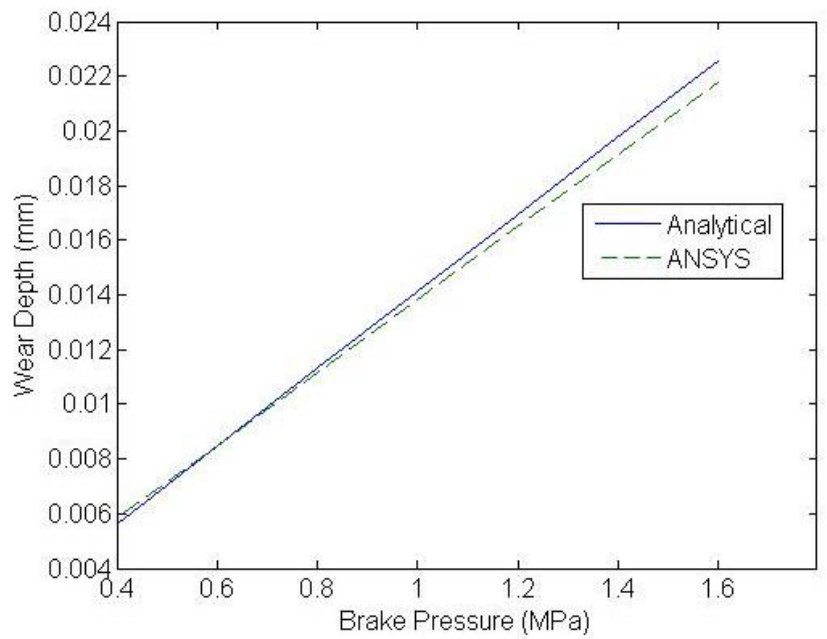

Fig.19. wear depth without temperature effect versus brake pressure

\section{Wear Depth by Thermal-Structural Effects}

The wear depth of disc brake with temperature effect is also done both methods results of maximum contact pressure with multiply by both velocity and wear coefficient. The analytical method of wear depth is done by using of Eq. (16) within different brake pressures. And it also done by ANSYS workbench by selection of maximum contact pressure result from each applied brake pressure and disc brake temperature then multiply it by both values of velocity at maximum contact pressure occur and wear coefficient. When we are observation between the analytical and ANSYS workbench software results, both show that the wear depth increases with the increase of brake pressure in Fig.20.

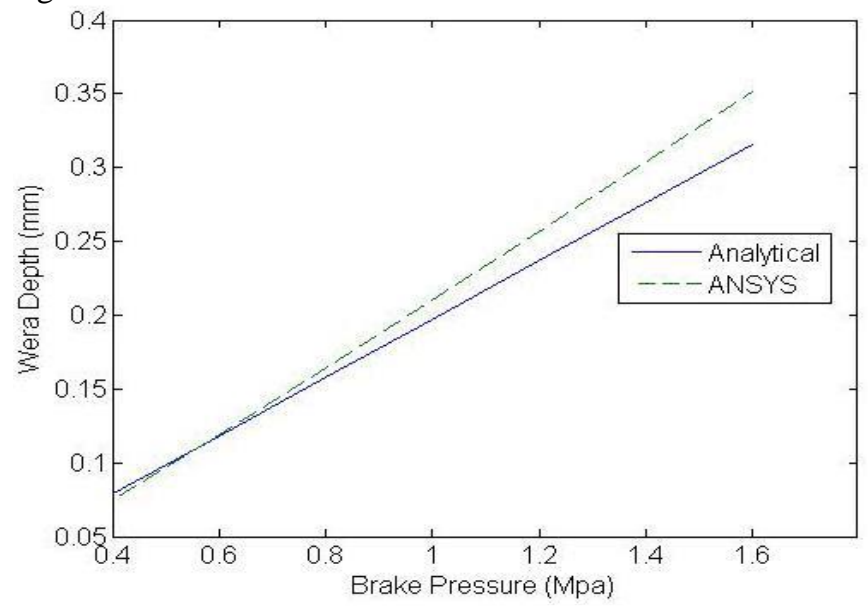

Fig.20.wear depth thermal-structural versus brake pressure

\section{V.CONCLUSION}

In this thesis work presented the analytical method and finite element method of surface wear on disc brake rotor without and within temperature effect. ANSYS workbench result with analytical method is done and similar result is obtained with reasonable accuracy.

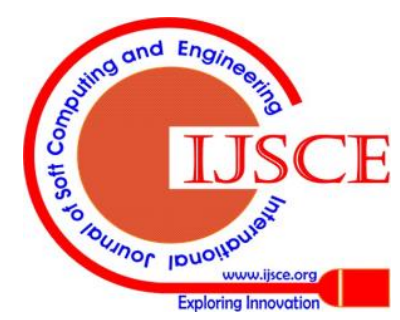


So that, researchers may use both analytical and ANSYS workbench to predict contact pressure and wear of mechanical components related to with or without effect of temperature. Generally from this thesis work the following conclusions can be figure out. Analytical method of contact temperature distribution along radial direction of disc brake was estimated. The analytical method of contact pressure, wear depth and von misses stress estimated as function of brake pressure. Both the analytical and ANSYS workbench results show that contact pressure, wear depth and von misses stress are increasing with the increase of brake pressure. The critical point of contact for disc brake in contact with pad brake is identified in both analytical and ANSYS workbench without or within temperature effects. When we observation, the effect of temperature in both methods of results, without temperature effect is less than that of within temperature effect in all parameters (contact pressure, wear depth and von misses stress). Contact pressure and von misses stress concentration at inner and outer radius of disc brake is large. Due to this reason the ventilated disc brake fail by wear, crack and fracture.

\section{REFERENCES}

1. Milenković, P.D., Jovanović, S.J., Janković, A.S., Milovanović, M.D. Vitošević, N.D., Đorđević, M.V., Raičević, M.M. (2010), "The influence of brake pads thermal conductivity on passenger car brake system efficiency", Thermal Science, vol.14, pp.221-230.

2. Adriaan, Neys (2012), "In-vehicle brake system temperature model", Master Thesis in the Master's programme in Automotive Engineering, Report No. 2012:38, Sweden.

3. Ćirović, V. and Aleksendrić, D. (2011), "Dynamic modelling of disc brake contact phenomena”, FME Transactions, Vol. 39, No. 1, pp. 177 183.

4. Bayer, R. G. (1994), "Mechanical wear preditction and prevention", New York.

5. Hutchings, I. M. (1992), "Friction and wear of engineering materials", CRC Press.

6. Belchocine, Ali (2012), "Thermal analysis of a solid brake disc", applied thermal engineering Vol. 32:59-67.

7. Belhocine, Ali (2014), "Structural and contact analysis of disc brake assembly during single stop brake event", Faculty of Mechanical Engineering, University of Sciences and the Technology of Oran, Algeria.

8. Podra, P., Andersson, S. (1999), "Simulating sliding wear with finite element method", Tribology International, 32:71-81.

9. Hairier, J. B.( 1955), “Themie analyaque de la chaleur", Paris, 1822 (English .trans. by A. Freeman, Dover Publications, Ncw York, 1955).

10. Majcherczak, D., Dufrenoy, P. and Berthier, Y. (2007), "Tribological, thermal and mechanical coupling aspects of the dry sliding contact", Tribol Int 40:834-843. doi: 10.1016/j.triboint.2006.08.004.

11. Khalid, M.K., Mansor, M.R., Abdul Kudus, S.I., Tahir, M. M., Hassan, M. Z. (2011), "Performance investigation of the UTeM ecocar disc brake system", International Journal of Engineering and Technology, Vol. 11, No. 6, pp. 1-6.

12. Limpert, R. (1999), "Brake design and safety", 2nd Edition, Warrendale, Pennsylvania, Society of Automotive Engineering Inc., pp. 137-144.

13. Johnson, K. L. and Johnson, K. K. L. (1987), "Contact mechanics", Cambridge University press.

14. Limpert, R. (1975), "Cooling analysis of disc brake rotors", SAE Paper No. 751014, Truck Meeting, Philadelphia.

15. Tian, X. and Kennedy, F. E. (1994), "Maximum and average flash temperature in sliding contacts", ASME J. Tribol., vol. 116, pp. 167173.

16. Hertz, H. (1881), "On the contact of elastic solids", J. reine angew. Math, 92(156-171):110

\section{AUTHORS PROFILE}

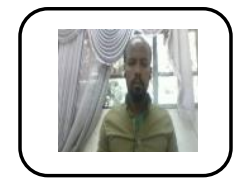

Hailemariam Shegawu Abebawu

MS.c in Mechanical Design

Wollo University, Kombolcha Institute of technology, Department of Mechanical Engineering

\section{Contact}

Wollo University, P.O.Box 208,

Wollo University, Ethiopia, Department of Mechanical Engineering Phone: +251 (0) 331190880

Cell Phone: 251 (0) 921381982

Fax: +251 (0) 331190880

\section{Biography}

Hailemariam Shegawu Abebawu, 33 years old, is mechanical engineer with specialization in mechanical design working at Wollo university. He received his bachelor in mechanical engineering in 2009 at Arba-Minch University and master degree in mechanical design in 2014 at Addis Abeba University. During his M.Sc period, he has focused his research on contact and wear of machine elements. After a post-graduate position at Ethiopian institute of mechanical , Ethiopia from 2010 to 2011 Assistance lecture Debre-Markos University, department of mechanical engineering . He joined Debre-Markos University, department of mechanical engineering as Mechanical engineering Lecturer from 20152017. From that time on, He continued his research activities mainly centered on contact and wear of parts.. He has been advising graduating class students thesis on various topicsrelated to machine design and development. But, at 2018 He asked transfer from Debre-Markos University to Wollo University.He currently engaged on contact stress due to pressure and temeperature lead to wear failure.

Current Research

- $\quad$ Design of shaft for stress and deflection by analytical and finite element method

- Design of helical gear for stresses and surface wear by analytical and finite element method

Interested topics

- $\quad$ wear failure analysis for mechanical components

- $\quad$ crack failure analysis for mechanical elements

- Vibration failure for mechanical parts

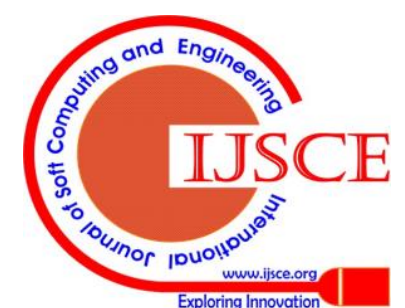

